\title{
Lethal control of African lions (Panthera leo): local and regional population impacts
}

\author{
Rosie Woodroffe ${ }^{1, \dagger}$ and Laurence G. Frank ${ }^{2}$ \\ ${ }^{1}$ Department of Wildlife, Fish \& Conservation Biology, University of California, One Shields Avenue, Davis, CA 95616-8751, USA \\ 2 Museum of Vertebrate Zoology, University of California, Berkeley, CA 94720, USA \\ (Received 9 June 2004; accepted 11 August 2004)
}

\begin{abstract}
Large carnivores have declined worldwide, largely through conflict with people. Here, we quantify the impact of lethal control, associated with livestock depredation, on a population of African lions (Panthera leo) living outside protected areas. Farmers shot lions only in response to livestock attacks. Nevertheless, adult mortality was high and a simple model predicted that the population was marginally stable or slowly declining. Mortality was four times higher among lions radio-collared in association with attacks on livestock, than among lions with no known history of stock killing, suggesting that some animals were habitual stock killers. Known stock killers also experienced lower reproductive success; hence there was strong artificial selection against stockkilling behaviour. In addition, mortality was higher among lions whose home ranges overlapped a property where non-traditional livestock husbandry was associated with chronic depredation by lions. This $180 \mathrm{~km}^{2}$ ranch acted as a sink that directly affected lions over more than $2000 \mathrm{~km}^{2}$ and may have undermined the viability of the study population. Our results suggest that sustainable coexistence of lions and people demands livestock husbandry that effectively deters predators from acquiring stock-killing behaviour, but that lethal control may play an important role in avoiding the spread of such behaviours through the population.
\end{abstract}

\section{INTRODUCTION}

As human populations have expanded and developed, all of the world's large carnivores have experienced major contractions in their geographical ranges, often becoming confined to areas (particularly protected areas) where human densities are low (Linnell, Swenson \& Andersen, 2001; Woodroffe, 2001). Human impacts on large carnivore populations extend even into protected areas, particularly for wide-ranging species that often range beyond reserve boundaries. Such species are vulnerable to being killed, deliberately or accidentally, by people in adjoining unprotected lands. The resulting edge effect may be severe enough to bring about the extinction of nominally protected populations (Woodroffe \& Ginsberg, 1998).

Against this background, effective conservation of large carnivores - both inside and outside reserves - demands the resolution of conflicts between people and predators. The extent to which this is achievable depends upon whether predators' impact on human lives and livelihoods can be reduced to a level that local people will tolerate, without reducing predator populations to unsustainably low levels. As a starting point, there is a need to determine

${ }^{\dagger}$ All correspondence to R. Woodroffe. Tel: 530-754-9513; Fax: 530752-4154; E-mail: rwoodroffe@ucdavis.edu whether existing levels of lethal control can be sustained by wild populations.

In this study, we quantify the impact of lethal control of African lions (Panthera leo), associated with depredation on livestock, on a population living outside protected areas. Lions can reach high densities inside reserves (e.g. Makacha \& Schaller, 1969; Ogutu \& Dublin, 2002), but tend to fare poorly outside protected areas, where they are often the first large carnivore species to disappear (Woodroffe, 2001). As Africa's largest carnivore, lions play an important role in structuring terrestrial communities (Mills, Biggs \& Whyte, 1995; Sinclair, 2003) and are also a crucial component of Africa's tourism industry (Western \& Henry, 1979). Hence, in addition to their intrinsic value, there are important ecological and financial incentives for conserving lions.

\section{STUDY AREA AND METHODS}

The study was carried out in an area of approximately $5000 \mathrm{~km}^{2}$ in Laikipia District, northern Kenya $\left(37^{\circ} 2^{\prime} \mathrm{E}\right.$, $\left.0^{\circ} 6^{\prime} \mathrm{N}\right)$. Laikipia is an area of semi-arid bush land and savanna, used for commercial ranching and subsistence pastoralism as well as for tourism and small-scale agriculture. The mean size of properties in the study area was $132 \mathrm{~km}^{2}$ (range $10-383 \mathrm{~km}^{2}$ ). None of the area is 
Table 1. Causes of mortality (and other losses from the study population) among radio-collared lions and uncollared members of groups that contained collared lions

\begin{tabular}{lllllll}
\hline & \multicolumn{2}{c}{ Collared adults } & & \multicolumn{2}{c}{ Uncollared adults } & \\
\cline { 2 - 3 } & Females & Males & & Females & Males & Cubs \\
\hline Killed by other lions & 0 & 1 & & 0 & 0 & 1 \\
Shot & 8 & 6 & & 3 & 6 & 5 \\
Apparently killed by people & 2 & 1 & & 0 & 1 & 0 \\
Assumed starved when rest of group shot & 0 & 0 & & 0 & 0 & 1 \\
Translocated to Meru & 1 & 1 & & 1 & 3 & 3 \\
Taken into captivity when mother shot & 0 & 0 & & 0 & 0 & 2 \\
\hline
\end{tabular}

formally protected. Although wildlife is more abundant in Laikipia than in surrounding districts (Georgiadis \& Ojwang', 2001), livestock greatly out-number wild ungulates: a 2003 aerial census estimated that Laikipia supported approximately 36000 zebras (Equus burchelli), 3000 elephants (Loxodonta africana) and 2000 buffalo (Syncerus caffer), with approximately 156000 cattle and 474000 sheep and goats (Georgiadis, Olwero \& Ojwang', $2003 b$ ). Lions in the study area prefer commercial ranchland over adjoining pastoral lands (Frank, Woodroffe \& Ogada, 2005), probably because the density of wild ungulate prey is markedly higher in these areas (Khaemba et al., 2001). Predation on livestock is an important cause of human-wildlife conflict (Frank, 1998; Ogada et al., 2003; Frank et al., in press), and lions may be legally killed in defense of human life or livestock (Republic of Kenya, 1989).

This study was carried out during 1998-2002. We captured lions by free darting (Mills, 1996), in foot snares (Frank, Simpson \& Woodroffe, 2003) and occasionally in cage traps. We captured lions on 11 properties (mean 5.3 lions/property, range 1-17). Of the 58 lions radiocollared, 16 were captured as they returned to the carcasses of livestock killed the previous night. All lions were uniquely marked using a system of ear notches; all adults were fitted with radio-collars containing mortality sensors (Telonics, Mesa, AZ).

We located radio-collared lions approximately weekly using aerial telemetry. If any animals could not be located for 2 successive weeks, we flew more widely to locate them; however six lions were lost due to dispersal or collar failure. If any collars were emitting a mortality signal, we immediately located them on the ground; however most mortalities (all shootings: Table 1) were reported to us immediately by farmers. We located lions on the ground to record group composition, including the presence and survival of cubs. We also recorded sightings by ranch managers and tour guides who used their own radiotelemetry receivers to monitor animals that we had radio-collared. In no case did farmers use telemetry equipment to locate and kill lions.

We considered marked animals to be lost to the population if they were known to have died (carcass or radio-collar recovered), or to have been translocated away. All translocated animals were taken by the Kenya Wildlife Service to Meru National Park, approximately $100 \mathrm{~km}$ from the study area. Five of the six adults translocated to Meru were fitted with radio-collars; all were reported to have died following translocation to this park, which already sustains a high density of resident lions (M. Jenkins, Warden Meru National Park, pers. comm.). Four animals that were only radio-collared on the day of translocation were excluded from the mortality analyses presented here.

We estimated adult mortality from radiotelemetry data using an extension of the Kaplan-Meier procedure to permit staggered entry of animals (Pollock et al., 1989). We compared mortality rates between different categories of lions using a log-rank test, which gives a test statistic distributed as $\chi^{2}$ (Pollock et al., 1989).

We estimated females' cub production from sightings of radio-collared females accompanied by small cubs. This would tend to miss cubs that died when they were very young. We omitted females from the analysis if observations were too infrequent to be sure whether or not they had produced cubs.

We estimated cub and yearling survival as the proportion of radio-collared females' cubs that were still accompanying their mothers at the ages of 12 and 24 months, respectively. Lions become large enough to radiocollar at around 30 months, so animals aged more than 24 months were assumed to experience 'adult' mortality. Juvenile sex ratio was based on the gender of all animals under 24 months that could be sexed. Since cubs become easier to sex as they grow older, this estimate would be biased if there was differential early mortality of male and female cubs. We used the natality and mortality data to construct a simple Leslie-matrix based model and used this to estimate $\lambda$, the annual rate of population growth.

Since adult mortality varied in different parts of the study area, we investigated whether lions avoided a particular ranch where mortality was high. We assessed lions' habitat use from radiotelemetry data using compositional analysis (Aebischer, Robertson \& Kenward, 1993). We considered a lion to have access to the ranch in question if that lion's home range (calculated as a $100 \%$ minimum convex polygon: Kenward, 1987) overlapped any part of that property. Out of 58 lions radio-collared, $15 \mathrm{had}$ access to this ranch. Five of these were omitted from the analysis because fewer than 15 radio-locations were available; the mean number of locations for the remaining 10 lions was 35 (range 16-55). We calculated the proportion of each lion's home range that covered the ranch in question and used this to calculate a log-ratio 
Table 2. Vital rates of lions recorded in this study

\begin{tabular}{llllll}
\hline Type of lion & $\begin{array}{l}\text { Adult mortality } \\
(\%)(95 \% \text { CI })\end{array}$ & $\begin{array}{l}\text { Cub } \\
\text { production }\end{array}$ & $\begin{array}{l}\text { Cub } \\
\text { mortality (\%) }\end{array}$ & $\begin{array}{l}\text { Yearling } \\
\text { mortality (\%) }\end{array}$ & $\lambda$ \\
\hline Population total & $\begin{array}{l}19.4 \\
(12.3-28.3 \%)\end{array}$ & 0.858 & 23 & 17 & 0.95 \\
Known stock killer & $\begin{array}{l}49.0 \\
(26.4-72.1 \%)\end{array}$ & 0.231 & 67 & & $0.87-1.02)$ \\
& 12.9 & & & 17 & $(0.33-0.76)$ \\
$\begin{array}{l}\text { Not known stock } \\
\text { killer }\end{array}$ & $(6.7-21.9 \%)$ & 0.981 & 13 & & 1.05 \\
$\begin{array}{c}\text { Used problem } \\
\text { ranch }\end{array}$ & $\begin{array}{l}39.0 \\
(21-59.7 \%)\end{array}$ & & & 75 & $(0.96-1.10)$ \\
$\begin{array}{l}\text { Never on problem } \\
\text { ranch }\end{array}$ & $\begin{array}{l}12.9 \\
(6.4-22.4 \%)\end{array}$ & & 23 & 5 & 0.68 \\
\hline
\end{tabular}

Adult mortality and cub production per female are annual rates; cub mortality is for the first 12 months of life, yearling mortality is for $12-24$ months.

'Known stock killers' are those lions that were initially radio-collared returning to a livestock kill; lions listed as 'not known stock killers' were collared under other circumstances, although some of them did subsequently kill livestock. The same lions are also re-classified according to whether or not they were ever located on a single 'problem' ranch with a chronic history of livestock depredation. Within the two classifications, separate vital rates are only reported if they were found to be significantly different.

Values of $\lambda$, the annual population growth rate, are calculated from the vital rates listed; they are reported along with upper and lower estimates calculated using the upper and lower $95 \%$ confidence limits (CI) of adult mortality estimates.

of its available habitat composition (Aebischer et al., 1993). This was then compared with the log-ratio of its utilised habitat composition, calculated from the number of locations actually falling on the ranch. A significant difference between these $\log$ ratios would indicate that lions were preferentially using (or avoiding) that particular ranch (Aebischer et al., 1993).

We also compared lion mortality with rainfall; rainfall data were collected at Mpala Research Centre, using standard techniques.

\section{RESULTS}

\section{Characteristics of stock-killing lions}

There was no sex bias in the proportion of lions radiocollared returning to livestock kills ( 10 out of 32 females (31\%), compared with 6 out of 26 males $(23 \%) ; \chi^{2}=0.16$, d.f. $=1, P=0.69$ ). However, there was a trend suggesting that male stock killers may have been younger than males collared in other circumstances ( 0 out of 6 stock-killing males had full manes, compared with 10 out of 20 other males; Fisher exact $P=0.053)$. There was no such trend for females (5 out of 10 stock-killing females $(50 \%)$ showed evidence of past lactation, compared with 11 out of 22 other females $(50 \%)$ ).

\section{Causes of mortality}

Of the 58 lions that we collared, $14(24 \%)$ were shot (Table 1); circumstantial evidence suggested that three more were also killed by people (e.g. radio-collar found with locking bolts unscrewed). Only one collared lion was recorded as having died from natural causes. We also recorded the deaths of a further 10 adults and seven cubs that were uncollared members of groups that contained collared animals; all but one of these were killed by people (Table 1). In addition to this mortality, two collared adults and seven previously uncollared lions, were lost to the population when the Kenya Wildlife Service translocated them to Meru. Two cubs were taken into captivity after their (collared) mother was shot.

Fourteen collared and 14 uncollared lions were shot on 12 different properties, with a maximum of five collared and five uncollared lions shot on a single property in the course of the study. There was a significant positive correlation between the number of collared and uncollared lions known to have been shot on particular properties ( $\mathrm{r}=0.67, n=12$ properties, $P=0.015$ ). All shootings occurred on commercial ranches; during this study period only one collared lion (out of 17) died on community lands (which lions tend to avoid: Frank et al., in press) and was presumed poisoned.

We were able to examine 22 out of 27 lions shot in association with attacks on livestock. Of these, we could confirm that $21(95 \%)$ had been present at a livestock kill (they were shot at the kill, or had livestock remains in their stomachs). However, four of these, and a fifth shot away from a livestock kill, were cubs too small to have made kills themselves.

\section{Adult mortality}

Overall mortality of radio-collared lions was $19.4 \%$ (exact binomial 95\% confidence interval $(\mathrm{CI})=12.3$ 28.3\%: Table 2). There was no significant difference in 
the mortality experienced by males $(24.2 \%, \mathrm{CI}=11.9$ $40.9 \%)$ and females $(16.6 \%, \mathrm{CI}=8.7-27.8 \%$; log rank test $\chi^{2}=0.75$, d.f. $=1, P=0.39$ ).

Mortality was significantly higher for lions that were collared returning to livestock kills (Table 2: $49.0 \%$, $\mathrm{CI}=26.4-72.1 \%$ ), than for those with no known history of killing livestock at the time of collaring $(12.9 \%, \mathrm{CI}=6.7-$ $21.9 \% ; \chi^{2}=12.85$, d.f. $=1, P=0.0003$ ).

Mortality of adult lions also varied between different parts of the study area. In particular, mortality was higher among lions whose home ranges overlapped a particular property with a chronic problem of losing livestock to lions (Table 2: $39.0 \%, \mathrm{CI}=21.0-59.7 \%$ ), than among lions that never visited this property $(12.9 \%, \mathrm{CI}=6.4-$ $22.4 \% ; \log$ rank test $\chi^{2}=8.77$, d.f. $\left.=1, P=0.003\right)$. When mortality was analysed separately for lions that did, and did not, use this property, the tendency for animals with a known history of stock killing to experience higher mortality remained (lions not using the problem property, $\log$ rank test $\chi^{2}=5.02$, d.f. $=1, P=0.025$; lions using the problem property, $\chi^{2}=3.70$, d.f. $=1, P=0.054$ ).

We also compared adult mortality with rainfall. Since there were wide confidence intervals around mortality estimates for particular months, we categorised months simply as having no deaths of collared lions, or one or more deaths, excluding all months during which fewer than 20 lions were being monitored. Deaths were significantly less likely to occur in months when less than $50 \mathrm{~mm}$ of rain had fallen during the previous 3 months ( 0 deaths in 9 months), than when rainfall had exceeded $50 \mathrm{~mm}$ (10 deaths in 27 months; Fisher exact $P=0.039$ ). In particular, a period of low lion mortality coincided with a prolonged drought during 2000-2001, followed by much higher mortality in 2001 when the rains returned.

\section{Cub production and sex ratio}

We were able to monitor the cub production of 28 collared females, for a combined total of 52.5 femaleyears. During this period, a minimum of 45 cubs was born, giving an average of 0.858 cubs per female-year (Table 2). This is likely to be an under-estimate of the true number of cubs born, since we could only count cubs large enough to be seen accompanying females. Our measure of cub production was significantly lower among females collared returning to livestock kills ( 2 cubs in 104 months, or $0.231 \mathrm{cubs} /$ female/year: Table 2), than in those with no known history of killing livestock at the time of collaring (43 cubs in 526 months, or 0.981 cubs/female/year: $\chi^{2}=4.75$, d.f. $=1, P=0.029$ ). There was no significant difference in cub production between females whose home ranges overlapped the property with a chronic problem of livestock loss and those which did not visit this property $\left(\chi^{2}=0.53\right.$, d.f. $\left.=1, P=0.47\right)$.

We were able to sex 39 cubs in 18 litters. Twelve of these $(30.8 \%)$ were female, a significant deviation from a $1: 1$ sex ratio $\left(\chi^{2}=5.77\right.$, d.f. $\left.=1, P=0.016\right)$. Hence, the annual production of female cubs per radio-collared female was $0.264(=0.858 \times 0.308)$.

\section{Juvenile survival}

We were able to monitor the survival of 30 cubs in 12 litters. Of these, 23 (77\%) survived to 12 months of age, of which $19(83 \%)$ subsequently survived to 24 months (Table 2).

Survival was significantly lower among cubs born to mothers who were collared as livestock killers ( 2 out of 6 cubs (33\%) survived to 12 months) than among females collared under other circumstances (21 out of 24 cubs (88\%) survived; $\chi^{2}=5.14$, d.f. $=1, P=0.023$ ), although there was no corresponding effect on the survival of yearlings (stock killers: 1 out of 2 cubs $(50 \%)$ survived 12-24 months; other females: 18 out of 21 (86\%) survived; $\chi^{2}=0.12$, d.f. $\left.=1, p=0.73\right)$. Conversely, there was no difference in the survival of cubs born to mothers whose home ranges overlapped the property suffering chronic livestock depredation (4 out of 6 cubs $(67 \%)$ survived) and those whose mothers did not visit this property (19 out of 24 cubs (79\%) survived; $\chi^{2}=0.01$, d.f. $=1, P=0.91$ ), but yearlings born to mothers frequenting the problem property experienced significantly higher mortality ( 1 out of $4(25 \%)$ survived $12-24$ months) than those whose mothers never visited this property (18 out of $19(95 \%)$ yearlings survived; $\chi^{2}=7.02$, d.f. $=1, P=0.008$ ).

\section{Population growth rate}

Based on population-wide estimates of vital rates (Table 2), a simple Leslie matrix model predicted $\lambda=0.95$, i.e. approximately a $5 \%$ population decline each year. This estimate must be treated with caution, since it is based on rather imprecise estimates of vital rates and also assumes that the proportions of stock-killers and animals visiting the problem ranch are representative of the population total. If population growth rate is recalculated using the upper and lower $95 \%$ confidence limits on adult mortality, rather than the mean, $\lambda$ may be as high as $1.02(2 \%$ growth per year) or as low as 0.87 (13\% decline per year: Table 2$)$. Despite this imprecision, calculation of $\lambda$ for different subpopulations has heuristic value.

The elevated mortality and reduced recruitment experienced by lions with a known history of killing livestock led to a prediction that this subset of the population should decline $(\lambda=0.54$ : Table 2$)$. Indeed, the mortality of stock-killing lions was sufficiently high that their population was still predicted to decline $(\lambda=0.92)$ even if recruitment rates were assumed to be the same as those among lions with no history of stock killing, and if the lowest $95 \%$ confidence limit on adult mortality was used to calculate $\lambda$ (see Table 2 for parameter values). By contrast, the model predicts $\lambda=1.05$ (5\% annual increase, range $3 \%$ decline to $12 \%$ increase: Table 2 ) for lions that were not initially radio-collared as stock killers.

The subset of the population whose home ranges overlapped the property with a chronic problem of livestock loss was likewise projected to decline $(\lambda=0.68$ : Table 2). Once again, even using the most conservative estimates of vital rates (the lower $95 \%$ confidence limit on adult mortality and assuming recruitment equal to that 
of lions not using the problem property), did not raise $\lambda$ above unity $(\lambda=0.96)$. By contrast, the model estimated $\lambda$ for the subset of the lion population not using this property to be 1.03 (3\% annual increase: Table 2).

We investigated the sensitivity of $\lambda$ to varying vital rates, altering one at a time while holding the others constant. These sensitivity analyses suggest a strong impact of adult mortality on $\lambda$. With adult mortality held constant at the observed population average, cub production would have to be increased substantially (above that recorded in the Serengeti National Park) to achieve $\lambda=1$ (Fig. 1(a)). With the observed birth rate, population stability or growth $(\lambda \geq 1)$ could not be achieved even with zero cub or yearling mortality (Fig. 1(b),(c)). By contrast, reducing adult mortality - which is markedly higher in this population than in any population previously studied (Table 3 ) readily achieves population growth, even if cub production and cub mortality are held constant at the observed levels (Fig. 1).

\section{Avoidance of the 'problem' ranch by collared lions}

Since lions using one ranch with chronic livestock predation experienced elevated mortality, they might be expected to avoid this property. However, compositional analysis of radiotelemetry data showed no significant difference between the log-ratios of lions' available and utilised habitat composition (paired $t_{9}=0.06, P=0.96$ ), providing no evidence to support this hypothesis.

\section{DISCUSSION}

Our study indicates that this lion population is limited by lethal control. Only one out of 20 radio-collared lions lost to the population died of natural causes (Table 1) and adult mortality was markedly higher than that reported for lions studied inside protected areas (Table 3 ). Probably as a result, the density of lions in the area $\left(5-6 / 100 \mathrm{~km}^{2}\right.$ of occupied habitat; Frank et al., in press) is lower than that recorded in protected areas of comparable prey density (van Orsdol, Hanby \& Bygott, 1985).

Farmers shot lions only when lions killed livestock, usually waiting until several attacks had occurred before implementing lethal control. In most cases, ranchers tracked lions from a livestock kill, or waited for the lion to return to the carcass the following night. This selective removal underlies a positive correlation between the number of lions killed on each ranch and the number of livestock killed by lions (Ogada et al., 2003).

Our analyses revealed strong selection against stockkilling animals. Elevated adult mortality and reduced recruitment among these lions led to a prediction that this sub-set of the population should decline; by contrast, lions with no known history of killing livestock were projected to remain stable or increase in number (Table 2). It is unlikely that this difference was generated by farmers selectively shooting lions that they knew to be stock killers. Individual lions are difficult to recognise, particularly at night when most were shot. Farmers could
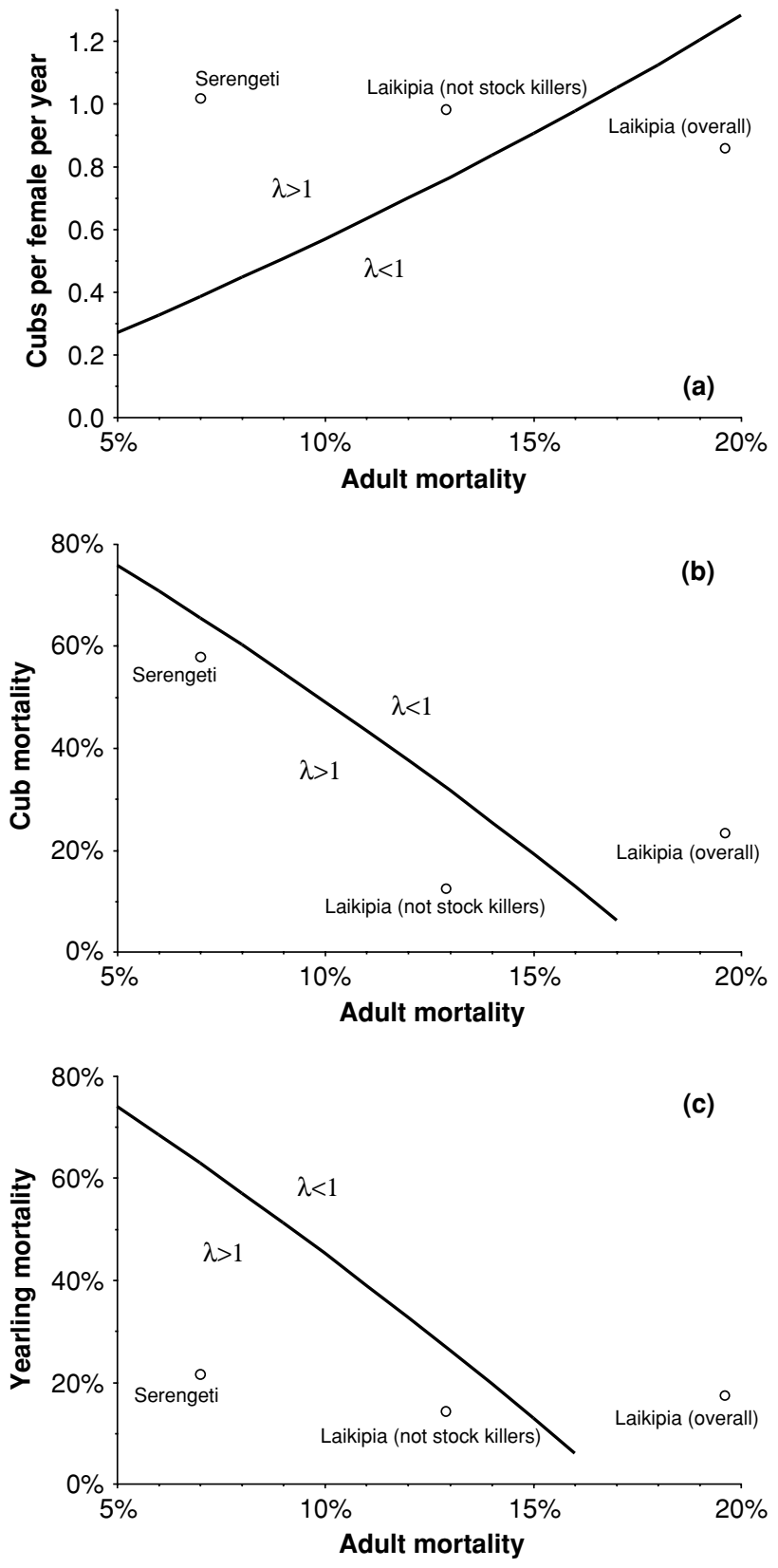

Fig. 1. Effects of varying adult mortality, cub production, cub mortality and yearling mortality on $\lambda$, the projected rate of population growth. Lines show $\lambda=1$ when (a) adult mortality and cub production are varied, keeping cub and yearling mortality constant at the population average (see Table 2 for parameters); (b) adult and cub mortality are varied, keeping cub production and yearling mortality constant at the population average and (c) adult and yearling mortality are varied, keeping cub production and mortality constant at the population average. Circles show the vital rates of the Laikipia lion population and, for comparison, vital rates from lions in the Serengeti National Park, Tanzania (data taken from Packer et al., 1988).

not use radio-collars as a visual cue to identify stock killers: five out of six properties where collared stock killers were shot were also used by collared lions with no history of stock killing. In only one case did a farmer use his radiotelemetry equipment to identify and shoot a 
Table 3. Adult mortality of African lions

\begin{tabular}{lllll}
\hline Study Area & Males (\%) & Females (\%) & Both sexes (\%) & Reference \\
\hline Laikipia District, Kenya & 24 & 17 & 19 & This study \\
Etosha National Park, Namibia & 10 & $3-8$ & & (Orford, Perrin \& Berry, 1988) \\
Serengeti National Park, Tanzania & $10^{*}$ & $7^{*}$ & - & (Packer et al., 1988) \\
Ngorongoro Crater, Tanzania & $21^{*}$ & $11^{*}$ & - & (Packer et al., 1988) \\
Okavango Delta, Botswana & & & 5 & (Winterbach \& Winterbach, 2002) \\
\hline
\end{tabular}

With the exception of this study, all of these data come from populations in formally or informally protected areas.

*Mortality calculated for lions aged 4-10 years.

known stock killer that was caught in a cage trap. Hence, our data tend to suggest that lions collared in association with attacks on livestock were more likely to be shot because they killed livestock repeatedly.

Like other studies of human-wildlife conflict (e.g. Stahl et al., 2002; Sitati et al., 2003; Treves et al., 2004; Woodroffe et al., 2005), we found that livestock predation by lions was patchily distributed. One ranch within the study area experienced chronic livestock losses; four lions were collared on this property, but 10 (five collared, five uncollared) were shot there in the course of the study - more than on any other property (range 1-4). It is important to draw attention to the extraordinary cooperation of this landowner and to point out that every lion killed on this property was shot in association with an attack on livestock. Adult lions with home ranges overlapping this $180 \mathrm{~km}^{2}$ ranch experienced mortality three times as high as that of lions that never visited the property and yearling mortality was also significantly higher (Table 2). Despite high localised mortality, lions did not avoid the ranch and lions that were shot were replaced by immigrants ( 5 out of 10 lions shot on the property were young males dispersing from neighbouring ranches). As a consequence of this high mortality, the subpopulation of lions that used this ranch - whose combined home ranges covered over $2000 \mathrm{~km}^{2}$ - was projected to decline. In essence, one property functioned as a sink that influenced a substantial proportion of the study area and may have affected the viability of the whole study population.

There are several possible explanations for the elevated livestock depredation observed on this one property. First, this property might sustain low densities of lions' natural prey. This hypothesis is not supported by data, however: seven aerial censuses carried out over a 16 year period indicate that the mean biomass of lions' wild ungulate prey on this ranch $\left(1617 \pm 247 \mathrm{~kg} / \mathrm{km}^{2}(\right.$ mean $\left.\pm \mathrm{SE})\right)$ is no lower than that on three neighbouring properties $(2031 \pm$ $334 \mathrm{~kg} / \mathrm{km}^{2}, 1922 \pm 343 \mathrm{~kg} / \mathrm{km}^{2}$ and $827 \pm 293 \mathrm{~kg} / \mathrm{km}^{2}$, respectively) that did not experience chronic depredation problems (N. J. Georgiadis \& J. G. N. Olwero, unpublished results). Alternatively, lions resident on this property might have developed a 'culture' of livestock killing. This appears unlikely, however, as the lions shot on the property originated in at least five different prides, some from other parts of the study area. A third, and more promising, explanation is that the high rate of livestock loss was associated with the husbandry measures used on this farm, which are necessary for the production of high quality sheep's wool. Traditional husbandry - involving confinement of livestock in thornbush corrals (bomas) at night - is highly effective in deterring predators (Ogada et al., 2003; Frank et al., in press), but cannot be used in wool production because non-native sheep accumulate high endoparasite burdens when kept in static bomas and because their wool becomes entangled in boma walls. Hence, wool producers use portable enclosures made of wire mesh, which are much less effective at excluding predators (Ogada et al., 2003; Frank et al., in press). This may foster the development of stock-killing behaviour. Since completion of the study reported here, sheep bomas have been modified to more effectively exclude lions. Preliminary results suggest that depredation rates are lower and the number of lions shot are also reduced as a consequence (L.G.F., unpublished results).

Our finding that lions collared as stock killers tend to be shot killing livestock supports Stander's (1990) contention that some lions become habitual stock killers while others rarely, if ever, kill livestock. This latter is somewhat surprising, given that livestock out-number wild ungulates across most of the district. One explanation, put forward by Linnell et al. (1999), is that husbandry practices demand that predators learn new foraging tactics to feed on livestock. In our study area, $89 \%$ of cattle and $85 \%$ of sheep and goats that are killed by lions are taken at night from bomas; this involves the lions either leaping into the boma or loitering outside until the cattle panic and break out (Ogada et al., 2003; Frank et al., in press). Such behaviours are not part of lions' natural hunting behaviour. If lions that show these behaviours tend to be shot and experience low reproductive success, then strong artificial selection could prevent stock-killing behaviour from spreading through the population. The preponderance of dispersal-age males in the sample of stock killers, however, indicates that lions can become stock killers without learning this behaviour from other animals. Measures such as efficient husbandry, which make stock killing a less profitable behaviour in the short term, are likely to reduce the proportion of lions that become habitual stock killers and subsequently have to be shot.

We found that lion mortality was low during periods of low rainfall. No mortality was recorded during a prolonged drought in 2000-2001 but, at the end of the drought, lion 
predation on livestock increased and, as a consequence, lion mortality also rose. This pattern probably reflects changes in the abundance of wild prey. During the drought itself, prey was abundant, in the form of livestock carcasses and under-nourished wildlife. Zebras, lions' principle prey in Laikipia, declined markedly (Georgiadis, Hack \& Turpin, 2003a), and this may have forced lions to seek alternative prey when the drought ended. Saberwal et al. (1994) described a similar pattern of increased lion predation on people following periods of drought around the Gir forest, India. Likewise, Hemson \& Macdonald (2002) showed that, in dryland areas of Botswana, livestock depredation by lions was most severe when wild prey migrated away and was least serious when they returned.

We found that cub sex ratios were significantly male biased. In other exploited lion populations, this has been attributed to high mortality of adult males as a result of trophy hunting (Yamazaki, 1996; Creel \& Creel, 1997; Whitman \& Packer, 1997). While overall male and female mortality rates were indistinguishable in this population, the apparent preponderance of young animals among stock-killing males (but not females) suggests a high mortality of pre-reproductive males that could help to explain the sex bias.

In conclusion, our study indicates that sustainable coexistence of people and lions is achievable outside protected areas. While our study population was, at best, only marginally stable, where good livestock husbandry was practiced, the lion population was projected to be stable or slightly increasing, even though habitual stock killers were subject to lethal control. Indeed, we speculate that selective removal of stock-killing lions may have helped to avoid the spread of such damaging behaviour through the population.

\section{Acknowledgements}

We dedicate this paper to the memory of Ian Ross and Jonathan Burchell, who died tracking lions in Laikipia in 2003. We would also like to thank Stephen Ekwanga, Leanne and Jamie Shannon, Meredith Evans, Peter and Hannelore Ragg and Jordan Lewis for assistance in the field and Claus Mortensen for providing detailed data on lion sightings. The manuscript was improved by comments from Matt Swarner and two anonymous reviewers. The project was supported by the Wildlife Conservation Society, National Geographic Society, African Wildlife Foundation, Busch Gardens, the Potrero Nuevo Fund and Mpala Research Centre. We also thank the ranchers of Laikipia for their extraordinary cooperation with this study. Lions were handled with permission from the Kenya Wildlife Service and under Animal Use Protocol No. R191 from the University of California, Berkeley.

\section{REFERENCES}

Aebischer, N. J., Robertson, P. A. \& Kenward, R. E. (1993). Compositional analysis of habitat use from animal radio-tracking data. Ecology 74: 1313-1325.
Creel, S. \& Creel, N. M. (1997). Lion density and population structure in the Selous Game Reserve: evaluation of hunting quotas and offtake. Afr. J. Ecol. 35: 83-93.

Frank, L. G. (1998). Living with lions: carnivore conservation and livestock in Laikipia District, Kenya. Unpublished Report. Development Alternatives, Inc.

Frank, L. G., Simpson, D. \& Woodroffe, R. (2003). Foot snares: an effective method for capturing African lions. Wildl. Soc. Bull. 39: 309-314.

Frank, L. G., Woodroffe, R. \& Ogada, M. O. (2005). People and predators in Laikipia District, Kenya. In People and wildlife - conflict or coexistence? Woodroffe, R., Thirgood, S. \& Rabinowitz, A. R. (Eds). Cambridge: Cambridge University Press. (in press).

Georgiadis, N. \& Ojwang', G. (2001). Numbers and distributions of large herbivores in Laikipia, Samburu and Isiolo Districts. Unpublished Report. Laikipia Wildlife Forum.

Georgiadis, N., Hack, M. \& Turpin, K. (2003a). The influence of rainfall on zebra population dynamics: implications for management. J. Appl. Ecol. 40: 125-136.

Georgiadis, N., Olwero, N. \& Ojwang', G. (2003b). Numbers and distributions of large herbivores in Laikipia District, Leroghi and Lewa Conservancy. Unpublished Report. Laikipia Wildlife Forum.

Hemson, G. \& Macdonald, D. W. (2002). Cattle predation by lions in the Makgadikgadi - some patterns and parameters. In Lion conservation research-Workshop 2: modelling conflict:10-12. Loveridge, A. J., Lynam, T. \& Macdonald, D. W. (Eds). Oxford: Wildlife Conservation Research Unit.

Kenward, R. E. (1987). Wildlife radio tagging: equipment, field techniques and data analysis. Orlando: Academic Press.

Khaemba, W. M., Stein, A., Rasch, D., De Leeuw, J. \& Georgiadis, N. (2001). Empirically simulated study to compare and validate sampling methods used in aerial surveys of wildlife populations. Afr. J. Ecol. 39: 374-382.

Linnell, J. D. C., Odden, J., Smith, M. E., Aames, R. \& Swenson, J. E. (1999). Large carnivores that kill livestock: do 'problem individuals' really exist? Wildl. Soc. Bull. 27: 698-705.

Linnell, J. D. C., Swenson, J. E. \& Andersen, R. (2001). Predators and people: conservation of large carnivores is possible at high human densities if management policy is favourable. Anim. Conserv. 4: 345-349.

Makacha, S. \& Schaller, G. B. (1969). Observations on lions in the Lake Manyara National Park, Tanzania. East Afr. Wildl. J. 7: 99103.

Mills, M. G. L. (1996). Methodological advances in capture, census, and food habits studies of large African carnivores. In Carnivore behavior, ecology and evolution vol. II: 223-242. Gittleman, J. L. (Ed.). Ithaca: Cornell University Press

Mills, M. G. L., Biggs, H. C. \& Whyte, I. J. (1995). The relationship between rainfall, lion predation and population trends in African herbivores. Wildl. Res. 22: 75-87.

Ogada, M. O., Woodroffe, R., Oguge, N. \& Frank, L. G. (2003). Limiting depredation by African carnivores: the role of livestock husbandry. Conserv. Biol. 17: 1521-1530.

Ogutu, J. O. \& Dublin, H. T. (2002). Demography of lions in relation to prey and habitat in the Maasai Mara National Reserve, Kenya. Afr. J. Ecol. 40: 120-129.

Orford, H. J. L., Perrin, M. R. \& Berry, H. H. (1988). Contraception, reproduction and demography of free-ranging Etosha lions. J. Zool., Lond. 216: 717-733.

Packer, C., Herbst, L., Pusey, A. E., Bygott, J. D., Hanby, J. P., Cairns, S. J. \& Borgerhoff Mulder, M. (1988). Reproductive success of lions. In Reproductive success: 363-383. Clutton-Brock, T. H. (Ed.). Chicago: University of Chicago Press.

Pollock, K., Winterstein, S. R., Bunck, C. M. \& Curtis, P. D. (1989). Survival analysis in telemetry studies: the staggered entry design. J. Wildl. Mgmt. 53: 7-15.

Republic of Kenya (1989). The Wildlife (Conservation and Management Act) amended. Nairobi: Government Printer. 
Saberwal, V. K., Gibbs, J. P., Chellam, R. \& Johnsingh, A. J. T. (1994). Lion-human conflict in the Gir Forest, India. Conserv. Biol. 8: 501507.

Sinclair, A. R. E. (2003). Mammal population regulation, keystone processes and ecosystem dynamics. Phil. Trans. Roy. Soc. Lond. Ser. B: Biol. Sci. 358: 1729-1740.

Sitati, N. W., Walpole, M. J., Smith, R. J. \& Leader-Williams, N. (2003). Predicting spatial aspects of human-elephant conflict. J. Appl. Ecol. 40: 667-677.

Stahl, P., Vandel, J. M., Ruette, S., Coat, L., Coat, Y. \& Balestra, L. (2002). Factors affecting lynx predation on sheep in the French Jura. J. Appl. Ecol. 39: 204-216.

Stander, P. E. (1990). A suggested management strategy for stockraiding lions in Namibia. S. Afr. J. Wildl. Res. 20: 37-43.

Treves, A., Naughton-Treves, L., Harper, E. K., Mladenoff, D. J., Rose, R. A., Sickley, T. A. \& Wydeven, A. P. (2004). Predicting humancarnivore conflict: a spatial model derived from 25 years of data on wolf predation on livestock. Conserv. Biol. 18: 114-125.

van Orsdol, K. G., Hanby, J. P. \& Bygott, J. D. (1985). Ecological correlates of lion social organization (Panthera leo). J. Zool., Lond. 206: $97-112$.

Western, D. \& Henry, W. (1979). Economics and conservation in third world national parks. BioScience 29: 2764-2769.
Whitman, K. \& Packer, C. (1997). The effect of sport hunting on the social organisation of the African lion (Panthera leo). In Proceedings of a symposium on lions and leopards as game ranch animals: 177-183. van Heerden, J. (Ed.). Onderstepoort, South Africa: Wildlife Group of the South African Veterinary Association.

Winterbach, H. \& Winterbach, C. W. (2002). Okavango Delta lions: ecology, home range and population dynamics. In Lion conservation research - Workshop 2: modelling conflict: 83-4. Loveridge, A. J., Lynam, T. \& Macdonald, D. W. (Eds). Oxford: Wildlife Conservation Research Unit.

Woodroffe, R. (2001). Strategies for carnivore conservation: lessons from contemporary extinctions. In Carnivore conservation: 61-92. Gittleman, J. L., Funk, S., Macdonald, D. W. \& Wayne, R. K. (Eds). Cambridge: Cambridge University Press.

Woodroffe, R. \& Ginsberg, J. R. (1998). Edge effects and the extinction of populations inside protected areas. Science 280: 21262128.

Woodroffe, R., Lindsey, P. A., Romañach, S. S., Stein, A. \& ole Ranah, S. M. K. (2005). Livestock predation by endangered African wild dogs (Lycaon pictus) in northern Kenya. Biol. Conserv. (in press).

Yamazaki, K. (1996). Social variation of lions in a male-depopulated area in Zambia. J. Wildl. Mgmt. 60: 490-497. 